\title{
Health education in the Spanish education system
}

\author{
Encarnación Pedrero-García ${ }^{1 a}$ \\ ${ }^{1}$ Facultad de Ciencias Sociales, Universidad Pablo de Olavide, Crta. De Utrera, Km.1 Seville, ES- \\ 41013, Spain
}

\begin{abstract}
Health education is an instrument of Health Promotion that seeks to influence the development of healthy lifestyles by eliminating risk factors and thus influencing in a positive way the health of the population. One of the objectives of the educational system is to educate for the development of the integral health of the students as well as to provide the appropriate formation so that they have a healthy vital development from a physical perspective like psychological. To this end, the Ministry of Education, Culture and Sport and in collaboration with the Ministry of Health, Social Services and Equality work on the development of actions and the implementation of stable programs of education and health promotion in the school environment With the purpose of fomenting and supporting an educational model directed to the development of the integral health of the whole educative community.
\end{abstract}

Keywords: healty, education, spanish

\section{Introduction}

Education for Health, understood as part of Health Promotion, is an important segment of education in general and a means of promoting health. That is why the educational system is consolidating as one of the most appropriate places to implement Health Education programs in the community.

The need for Health Education to be present in school curricula became clear from the LOGSE [6]. The Educational Policy, which is reflected in the General Organic Law of the Educational System [6], emphasized the importance of giving it a cross-curricular treatment, thus constituting a wake-up call for educators regarding new curricular approaches in terms of Health and enabling in turn the adequacy of the educational system to the needs that a modern society has to generate health. The subsequent educational laws that followed LOPEG [9], LOCE [7] and LOE [8] are implicitly or explicitly implicit in the idea of maintaining this educational need.

Being aware that the educational system as a whole does not constitute the community, but it is part of it and it is in him that the habits and attitudes with which the students will

${ }^{\text {a } C o r r e s p o n d i n g ~ a u t h o r: ~ e p e d g a r @ u p o . e s ~}$ 
live their life later as adults. It is important, therefore, that the socializing process be given in coordinates that facilitate the appearance of all those skills that help the subject to live in fullness, encouraging the development of healthy habits that contribute to their personal and social development, ultimately their integral development.

Health education must be concretized in the school at the level of objectives, contents, activities, methodology and evaluation. In short, it should be formally considered within the status that the educational project of the centers contributes. Health Education understood as health promotion is an important part of education in general and a means of promoting health.

\section{Methodology}

The followed methodology is qualitative by using data analysis with the software Atlas.ti to review hundreds of documents on the subject and responds to the objectives that we propose with this investigation:

- Define health promoting schools.

- Determine their characteristics

- Analyze Health education in the Spanish educational curriculum

\subsection{Definition of health promoting schools}

The development of Health Education within the educational framework is endorsed by a number of well-known institutions such as WHO, UNESCO, UNICEF, the Council of Europe and the European Commission, as well as the Organization for Economic Cooperation and Development (OECD). All of these institutions consider it to be the most effective way of promoting the long-term adoption of healthy lifestyles and the only way for health education to reach the younger population (childhood, adolescence and early life) Youth), regardless of factors such as social class, gender, or the level of education achieved by parents.

This type of school is defined as "a human community that cares about the health of all its members: students, teachers and non-teaching staff as well as all those who relate to the school community" [15] and not only as efficient systems in producing education. On the other hand, for WHO [13] "A health promoting school is defined as one that constantly strengthens the characteristics that make it a healthy environment for living, learning and working.

The origin of this network is in the works carried out in the eighties of the last century within the Pilot Project on health education that had its continuity in the recommendations in the Conference on "Promotion of Education for Health", held in Strasbourg in September these proposals and guidelines are in line with the priorities set by WHO in the field of health promotion, as well as with the conclusions of the Dublin Conference on "Prevention and Health Education in Schools "sponsored by the European Economic Community [6]. According to its organization chart, in each country there is a network coordinator (who in Spain, member of the network since March 1993, is located in the CIDE).

\subsection{Characteristics of health promoting schools}

With respect to health promoting schools, we find that they have to meet a series of characteristics in order to be able to define them as such. Castillo Lemee [1, p.43] points out the following:

a) The health promotion school considers health education through all aspects of school life and its relationships with the community and not only in classroom activities. 
b) It is based on a comprehensive health model that includes the interactions between the physical, mental, social and environmental aspects.

c) It focuses on the active participation of students through a wide variety of methods that contribute to developing skills.

d) Recognize that the health of students is subject to multiple influences and takes into account pre-existing beliefs, values and attitudes.

e) Recognize that there are skills and processes that form the basis of all health improvement and include them as objectives of the school curriculum.

f) It tends to develop in the student a positive image of himself, and to increase his capacity for self-control, as basic elements of the promotion of good health.

g) Recognize the importance of the physical environment and its physiological and effective effects on students and school personnel.

h) See the promotion of health in the school related to the welfare of the school staff and recognize the role of example that plays with the child.

i) It considers the parents of the students as an indispensable support for the school in the promotion of health.

j) Engages school medical services to participate in the educational program and to help students make better use of the resources they can offer.

\subsection{Health education in the Spanish educational curriculum}

In Spain, regarding the teaching of Health Education for teachers and secondary school teachers, part of the approval of the General Organic Law of the LOGSE Educational System in 1990 [6]. From this moment we start To advance in the implementation of this subject in the curriculum of the Diploma of Teaching, and in the Degree in Education Sciences, today what would be the different degrees in Education and Pedagogy, constituted the subject in most cases as optional .

Health education is included in the curriculum as a transverse matter, that is, as a teaching that does not belong to a particular area of curriculum development, but must be present across the different areas. Through the different regional norms of development of curricula of the stages of infantile, primary, secondary education, Baccalaureate, adult education is based on the need for Health Education.

In secondary and upper secondary education, cross-curricularity is reflected in a holistic sense, emphasizing the need to implement an education in values and attitudes, taking into account the principle of integration of LOGSE [6], but without specifying what capacities of the different transversal themes, And especially the one of Education for the Health, must acquire the students at the end of this educational stage.

After the LOGSE [6] and some attempts at new unapproved educational laws, a new educational law appears, Organic Law 2/2006, of May 3, Education [8]. This law retains part of the LOGSE [6], some extremes of the Law of Quality [7].

The LOE [8] establishes, at all levels of compulsory education, objectives that aim to develop the affective and psychosocial capacities of students, to value and respect the gender aspects and the equality of rights and opportunities between men and women, to strengthen the habits of corporal care and health and to critically evaluate the social habits related to health, consumption, care of living beings and the environment.

In addition, all stages of the LOE [8] deal with important aspects of Health Education in the areas of: Knowledge of the environment, Natural Sciences, Physical Education and Citizenship Education. The school therefore has the responsibility of integrating health education in its projects, and this means above all promoting the value of health among all the groups that make up the school community, throughout the training period, so that healthy behaviors are facilitated, and the decision-making and personal choice of healthy 
lifestyles is promoted from the autonomy and the establishment of lasting positive attitudes towards health care.

\section{Research result}

The European Network of Health Promoting Schools aims to facilitate the adoption of healthy lifestyles in a health-friendly environment to the educational community by agreeing that a health promotion school is one that responds to the following objectives [10, p.65]:

a) To promote healthy lifestyles and to offer students and teachers options that are both realistic and attractive in terms of health.

b) Define clear goals of health promotion and safety for the whole school community.

c) Provide a framework and study aimed at health promotion, taking into account: the conditions of the school building, sports and recreational spaces, school canteens, security aspects of access, etc. .

d) Develop the sense of individual, family and social responsibility in relation to health.

e) Enable the full physical, psychic, and social development, and the acquisition of a positive image of itself in all students.

f) Promote good relations between all members of the educational community and the community with its environment.

g) Integrate health education in the Curriculum Project consistently, using methodologies that encourage the participation of students in the educational process.

h) To provide students with the knowledge and skills necessary to make responsible decisions regarding their personal health and to contribute to the development of the health and safety of their environment.

i) Identify and use existing resources in the community to develop actions in favor of health promotion.

j) Expand the concept of school health services to make them an educational resource that helps the community to properly use the health system.

These objectives respond to a precise conception of the educational function, which refers to the school institution must support its students so that, based on a formed and critical opinion, they can make their own decisions in a conscious and responsible manner, at the same time Who acquire the conceptual, procedural resources and skills that allow them to act with autonomy in the resolution of the problems that affect them in the field of health.

Therefore, the acquisition of skills, self-determination and community-oriented action are common concepts to health promotion and education when they are interpreted as a support to be socially critical, reflexive and questioning in the framework of a transformative educational culture. Such an orientation encourages many actors, in a school inserted in their community, to share their points of view and their experiences and to play their role in developing knowledge about their reality and how to modify it in the direction of increase their quality of life. In this way, the development of the concept School health promoter has become a fundamental principle in the orientation of the movements of Health Education [13].

Red SHE (Schools for Health in Europe network) aims to support organizations and professionals in the field of development and maintenance of health promotion in school, providing a European platform whose main objective is Support organizations and professionals in the development and maintenance of health promotion in schools in all 
countries. The network of Schools for Health in Europe focuses on making schools that promote health and school health a more integrated part of the policies that are developed between the education and health sectors in Europe.

Autonomic Networks of Health Promoting Schools: The participation of the different Autonomous Communities in networks promoting health is developed in two different ways. On the one hand, there are Communities that have created their own networks of health promoting schools, as in Aragon, the Canaries, Cantabria and Extremadura. Other Communities, however, are integrated into the European Network of Health Promoting Schools, through different calls. Such is the case of Asturias, Valencia and Navarre.

Specifically, in Spain, results show that 400-450 health promoting schools are currently part of this network, and the most active Spanish regions are Aragón, Canarias, Cantabria and Navarra.

Most centers belonging to this network include Health Education in the school curriculum, and school teachers and management teams are the ones who suggest the activities. It is then clear the training needs of these teachers on different intervention areas. Moreover, schools face obstacles that hinder development on Health Education programmes, namely lack of material, economic and staff resources. Hence the need of external professionals to support their programme developments. In short, the health promotion school is open to the community, integrates with its processes and uses the resources it can offer by associating it with its programs. The European Network of Health Promoting Schools aims to facilitate the adoption of healthy lifestyles in a health-friendly environment for the educational community.

\section{Conclusion}

There is increasing evidence that approaches are most effective when Include health education within a comprehensive school approach. These approaches create an environment of physical, social and learning support, which Students, families, communities and organizations. Teaching /Learning about any health issue, such as healthy eating or mental and emotional health, will require linking with broader initiatives on school life in general and the community, if they are to have an impact on behavior related to Health or the situation of the same in the long term.

The international literature review [4], [5] supports the effectiveness of schools approach to health, in terms of the results it can generate. West et al. [12] investigated the effects of school as a whole on student health behaviors. Their results also served to support the approach of health promoting schools. Stewart-Brown [11] concluded that school programs that were effective in changing youth health or health-related behaviors were those that involved activities in more than one area.

Specifically in the case of Spain, Garcia-Vazquez's research [3] concludes that there is sufficient evidence that a proper incorporation of the health education in the educative centres, following the criteria and recommendations of The European Network of Health Promoting Schools, produce positive effects on the students including health improvement.

The United Nations has recognized the potential of schools to influence not only the Educational situation of the youth, but also in their health and economic development. This is evident in the importance given to primary education Universal and the elimination of gender disparity in primary education as secondary, within the Millennium Development Goals. There is a link between good health, educational outcomes and the studies. There is also a well-established relationship between school the improvement of health [2]. These relationships imply that the improvement in efficiency in one sector can potentially benefit another sector, so that the Schools are an important place for both education and health. 


\section{References}

1. Castillo Lemee, F. La escuela promotora de salud. En A. García, (Coord.). Claves de Educación para la Salud. Murcia: DM, (1998).

2. Cohen, S. Social Relationships and Health. American Psychologist, 59(8), 676-684, (2004). https://doi.org/10.1037/0003-066X.59.8.676

3. García-Vázquez, J. Effects of the School for Health network on students' behaviour in Asturias (Spain). Health Promotion International, 32(2), 271-279, (2017). https://doi.org/10.1093/heapro/dau076

4. Leger, L.S. \& Nutbeam, D. A Model for Mapping Linkages Between Health and Education Agencies to Improve School Health. Journal of School Health. 70, 2, 45-50, (2000). http://doi.org/10.1111/j.1746-1561.2000.tb07239.x

5. Leger, L. S., Kolbe, L., Lee, A., McCall, D. and Young, I. School health promotion: achievements, challenges and priorities. In McQueen, D. and Jones, C. (eds), Global Perspectives on Health Promotion Effectiveness. Springer SciencepBusiness Media, LLC, New York, (2007).

6. Ley Orgánica 1/1990, de 3 de octubre, de Ordenación General del Sistema Educativo (BOE N ${ }^{\circ} .238,4$ de octubre de 1990).

7. Ley Orgánica 10/2002, de 23 de diciembre, de Calidad de la Educación (BOE No .307 , de 24 de diciembre de 2002).

8. Ley Orgánica 2/2006, de 3 de mayo, de Educación (BOE №. 106, de 4 de mayo de 2006).

9. Ley Orgánica 9/1995, de 20 de noviembre, de Participación, Evaluación y Gobierno de Centros Docentes (BOE N ${ }^{\circ} .278,21$ de noviembre de 1995).

10. Pedrero García, E. Educación para la Salud y Pedagogía de la Muerte. Tesis Doctoral. Sevilla: Universidad Pablo de Olavide, (2012).

11. Stewart-Brown, S. What is the evidence on school health promotion in improving health or preventing disease and, specifically, what is the effectiveness of the health promoting schools approach? Copenhagen, WHO Regional Office for Europe (Health Evidence Network report, (2006) http://www.euro.who.int/document/e88185.pdf

12. West, P., Sweeting, H., \& Leyland, A. School effects on pupils' health behaviours: evidence in support of the health promoting school. Research Papers in Education Policy and Practice, 19(3), 261-29, (2004). https://doi.org/http://dx.doi.org/10.1080/02671522.2004.10058645

13. Williams, M. y Young, I. (Eds.). Promotiong the health of Young people in Europe. Health Education in Schools: a trainign manual of teachers and others working with Young people. Edimburgo: WHO/HEBS, (1993).

14. World Health Organization. Health-Promoting Schools: a healthy setting for living, learning and working. Geneva: WHO, (1997).

15. Young, I. (Coord.). La educación para la Salud en el ámbito educativo. Madrid: Comisión Europea/MEC. Policopia, (1995). 